\title{
Keabsahan Akta Pinjam Meminjam Nama Perusahaan Antar Peserta Tender (Studi Kasus pada Putusan KPPU Nomor 41/KPPU- L/2008 dan Putusan KPPU Nomor 16/KPPU-L/2014)
}

\author{
Intan Nasta Dewi \\ Magister Kenotariatan Fakultas Hukum Universitas Islam Indonesia Yogyakarta Indonesia \\ Jln. Cik Di Tiro No. 1 Yogyakarta Indonesia \\ intannasta@gmail.com
}

\begin{abstract}
This study aims to examine the validity of the deed of loan between bidding companies and the notary's responsibility for the deed of loan made by the bidding companies. This is a normative legal research by using primary, secondary, and tertiary legal materials which are analyzed by qualitative descriptive methods. This research shows concluded that the KPPU's Decision Number 41/KPPUL/2008 concerning the Agreement made by PT. Pelita Jaya Mandiri with Abdul Wahid Soenge, and KPPU's Decision Number 16/KPPU-L/2014. The agreement made by CV. The parrot with Riza Febriant did not meet the objective requirements because they had violated Article 22 of Law Number 5 of 1999 on the Prohibition of Monopolistic Practices and Unfair Business Competition and the Presidential Regulation on the Procurement of Goods and Services, so that the agreement was null and void and the Notary could not be held responsible related to the deed because the deed of the parties is the will of the parties and the Notary is not a party to the deed.
\end{abstract}

Key Words: Bidding; borrowing of name; validity

\begin{abstract}
Abstrak
Penelitian ini bertujuan untuk mengkaji tentang keabsahan akta pinjam meminjam perusahaan antar peserta tender dan tanggung jawab notaris atas akta pinjam meminjam perusahaan yang dibuat oleh para peserta tender. Penelitian ini merupakan penelitian hukum normatif dengan menggunakan bahan hukum primer, sekunder, dan tersier yang dianalisis dengan metode diskriptif kualitatif. Penelitian ini menyimpulkan bahwa Putusan KPPU Nomor 41/KPPU-L/2008 tentang Perjanjian yang dibuat oleh PT. Pelita Jaya Mandiri dengan Abdul Wahid Soenge, dan Putusan KPPU Nomor 16/KPPU-L/2014 Perjanjian yang dibuat oleh CV. Burung Nuri dengan Riza Febriant tidak memenuhi syarat objektif karena telah melanggar Pasal 22 Undang-Undang Nomor 5 Tahun 1999 tentang Larangan Praktik Monopoli dan Persaingan Usaha Tidak Sehat serta Peraturan Presiden tentang Pengadaan Barang dan Jasa, sehingga perjanjian tersebut batal demi hukum dan Notaris tidak dapat bertanggungjawab terkait akta tersebut dikarenakan akta para pihak merupakan kehendak para pihak dan Notaris bukan pihak dalam akta tersebut.
\end{abstract}

Kata-kata Kunci: Keabsahan; pinjam nama; tender 


\section{Pendahuluan}

Undang-Undang Nomor 5 Tahun 1999 tentang Larangan Praktik Monopoli dan Persaingan Usaha Tidak Sehat selanjutnya disebut Undang-Undang Larangan Praktik Monopoli dan Persaingan Usaha Tidak Sehat melarang pelaku usaha melakukan tindakan tertentu, yakni melakukan perjanjian yang dilarang, kegiatan yang dilarang dan posisi dominan. Perjanjian yang dilarang diatur dalam Pasal 4 sampai dengan Pasal 16, antara lain oligopoli, penetapan harga, pembagian wilayah, pemboikotan, kartel, trust, oligopsoni, integrasi vertikal, perjanjian tertutup, dan perjanjian dengan pihak luar negeri. ${ }^{1}$ Selain itu, undangundang ini juga mengatur tentang kegiatan yang juga dapat mengakibatkan persaingan usaha tidak sehat. Undang-Undang Larangan Praktik Monopoli dan Persaingan Usaha Tidak Sehat memang tidak dijelaskan apa itu definisi dari "kegiatan" akan tetapi kegiatan dapat ditafsirkan sebagai perbuatan hukum sepihak yang dilakukan oleh satu pelaku usaha atau kelompok pelaku usaha tanpa adanya keterkaitan hubungan. ${ }^{2}$

Salah satu kegiatan yang dilarang dalam hukum persaingan usaha adalah persengkongkolan. Persekongkolan mempunyai karakteristik yakni terdapat kerja sama yang melibatkan dua atau lebih pelaku usaha yang secara bersama-sama melakukan tindakan melawan hukum. ${ }^{3}$ Terdapat tiga bentuk kegiatan persekongkolan yang dilarang oleh Undang-Undang Larangan Praktek Monopoli dan Persaingan Usaha Tidak Sehat, yaitu persekongkolan tender yang diatur dalam Pasal 22, persekongkolan untuk membocorkan rahasia dagang yang diatur dalam Pasal 23, dan persekongkolan untuk menghambat perdagangan dalam Pasal 24. ${ }^{4}$

Kegiatan bersekongkol untuk menentukan pemenang tender merupakan perbuatan curang. Pada dasarnya tender dan pemenangnya tidak dapat diatur dan bersifat rahasia. ${ }^{5}$ Berdasarkan ketentuan Pasal 22 Undang-Undang Larangan Praktik Monopoli dan Persaingan Usaha Tidak Sehat pelaku usaha dilarang bersekongkol dengan pihak lain untuk mengatur dan/atau menentukan pemenang tender sehingga dapat mengakibatkan terjadinya persaingan usaha tidak sehat. Pihak lain yang dimaksud tidak terbatas pemerintah saja, namun bisa juga pihak swasta atau pelaku usaha yang terkait dalam tender yang bersangkutan. 6

${ }^{1}$ Andi Fahmi Lubis, et.al, Hukum Persaingan Usaha antara Teks dan Konteks, Komisi Pengawas Persaingan Usaha, Jakarta, 2009, hlm. 87.

2 Rachmadi Usman, Hukum Persaingan Usaha Di Indonesia, Cetakan Pertama, Sinar Grafika, Jakarta, 2013, hlm. 368.

${ }^{3}$ Hery, SE, Hukum Bisnis, PT. Grasindo, Jakarta, 2020, hlm. 206.

4 Ibid., hlm. 204-205.

5 Alexander Thian, Hukum Dagang, CV. Andi Offset, Yogyakarta, 2021, hlm. 171.

6 Rachmadi usman, Op. Cit., hlm. 479. 
Salah satu cara yang dilakukan untuk melakukan persekongkolan tender adalah melakukan perjanjian pinjam meminjam nama perusahaan. Tindakan ini dimaksudkan untuk menjadikan suatu perusahaan tertentu menang tender lalu perusahaan yang kalah akan mendapatkan kompensasi dari perusahaan yang menang. Dalam melaksanakan tindakan pinjam meminjam nama perusahaan ini terkadang melibatkan Notaris. Hal mana salah satunya dapat diamati dalam Putusan KPPU Nomor 41/KPPU-L/2008 terkait pengadaan DVD Televisi Dinas Pendidikan Sumatera Utara dimana PT. Pelita Jaya Mandiri selaku pemenang Tender telah melakukan Persekongkolan Tender. Hal ini diperkuat dengan adanya Akta Perubahan Anggaran Dasar dan Surat Perjanjian Kerjasama yang dibuat oleh Notaris Adi Pinem dimana akta tersebut dibuat setelah PT. Pelita Jaya Mandiri dinyatakan memenangkan tender oleh panitia. Selain itu, dapat dilihat juga dalam kasus yang tertuang dalam Putusan KPPU Nomor 16/KPPU-L/2014 terkait pengadaan sarana TIK Media Pembelajaran Interaktif SD/SDLB di Kabupaten Probolinggo yang mana CV. Burung Nuri selaku pemenang tender telah membuat Perjanjian Kerja Sama dengan Riza Febriant yang dibuat oleh Notaris Moh. Sugiono dengan menciptakan persaingan semu dalam proses tender.

Berangkat dari permasalahan yang terjadi tersebut maka penulis dalam tulisan ini mengangkat judul “KEABSAHAN DARI AKTA PINJAM MEMINJAM PERUSAHAAN ANTAR PESERTA TENDER".

\section{Rumusan Masalah}

Permasalahan dalam penelitian ini adalah: pertama, bagaimana keabsahan akta pinjam meminjam perusahaan antar peserta tender menurut Putusan KPPU Nomor 41/KPPU-L/2008 dan Putusan KPPU Nomor 16/KPPU-L/2014? Kedua, bagaimana tanggung jawab Notaris atas akta pinjam meminjam perusahaan yang dibuat oleh para peserta tender terkait menurut Putusan KPPU Nomor 41/KPPUL/2008 dan Putusan KPPU Nomor 16/KPPU-L/2014?

\section{Tujuan Penelitian}

Berdasarkan rumusan permasalahan di atas maka tujuan dari penelitian ini adalah: pertama, untuk mengkaji dan menganalisis keabsahan akta pinjam meminjam perusahaan antar peserta tender. Kedua, untuk mengkaji dan menganalisis tanggung jawab Notaris atas akta pinjam meminjam perusahaan yang melibatkan para peserta tender. 


\section{Metode Penelitian}

Penelitian ini merupakan penelitian dengan mengkaji berbagai bahan hukum yakni bahan hukum primer, sekunder, dan tersier. Metode penelitian yang digunakan ialah yuridis normatif, yaitu pendekatan dari sudut pandang norma hukum serta di dukung oleh data empiris yaitu pendekatan dari sudut pandang hukum yang berlaku dalam masyarakat. Data yang terkumpul dari hasil penelitian ini dianalisis secara deskriptif kualitatif dengan menguraikan data yang diperoleh lalu ditata secara sistematis dalam wujud uraian kalimat yang diambil maknanya sebagai kesimpulan.

\section{Hasil Penelitian dan Pembahasan}

\section{Keabsahan Akta Pinjam Meminjam Perusahaan Antar Peserta Tender}

Dinas Pendidikan Sumatera Utara melakukan pengadaan TV, DVD, dan Antena dalam tahun anggaran 2007 melalui tender bersama 37 perusahaan pendaftar. Dalam pelaksanaan tender tersebut dilakukan penyaringan dan terpilih PT. Pelita Jaya Mandiri sebagai pemenang. Setelah pengumuman pemenang, Direktur dari PT. Pelita Jaya Mandiri bertemu dengan Abdul Wahid Soenge yang sedang mencari perusahaan untuk dipinjam bendera perusahaanya. Pada saat tersebut dilakukan kesepakatan bagi Abdul Wahid Soenge untuk menjalankan tender yang sudah dimenangkan PT. Pelita Jaya Mandiri dengan fee sebesar Rp. 20.000.000,00. Kesepakatan ini kemudian diperkuat melalui pembuatan akta ke Notaris Adi Pinem.

Dinas Pendidikan Kabupaten Probolinggo Provinsi Jawa Timur melalui panitia pengadaan barang dan jasa juga melakukan tender untuk pengadaan sarana TIK Media Pembelajaran Interaktif SD/SDLB pada tahun anggaran 2012. Diikuti oleh 25 peserta yang mendaftar dan terpilih 3 peserta yang memenuhi kualifikasi pengadaan tender tersebut, lalu ditetapkan pemenang tender adalah CV. Burung Nuri. Berdasarkan hasil pemeriksaan oleh KPPU CV. Burung Nuri memiliki direktur yang bernama Moh. Nori sebelumnya tidak mengetahui jika CV. Burung Nuri ini dinyatakan menang tender. Segala pendaftaran dan urusan tender dilakukan oleh Riza Febriant yang meminjam bendera CV. Burung Nuri. Selanjutnya demi memperkuat kesepakatan mereka maka dibuat perjanjian kerja sama No. 01 pada 28 April 2012 di hadapan Notaris Moh. Sugiono.

Berdasarkan kedua putusan KPPU yaitu Nomor 41/KPPU-L/2008 dan Nomor 16/KPPUL-L/2014 pembuktian tentang terjadinya persekongkolan tender dianalisis melalui unsur-unsur dalam Pasal 22 Undang-Undang Larangan Praktik Monopoli dan Persaingan Usaha Tidak Sehat. Unsur-unsur tersebut dijabarkan sebagai berikut. 
a. Unsur Pelaku Usaha

Bahwa unsur pelaku usaha yang dimaksud dalam putusan KPPU Nomor 41/KPPU-L/2008 adalah PT. Pelita Jaya Mandiri dan Abdul Wahid, sedangkan unsur Pelaku Usaha dalam Putusan KPPU Nomor 16/KPPUL/2014 adalah CV. Burung Nuri, CV. Satriya, dan CV. Ferro.

b. Unsur Bersekongkol

Bahwa Unsur Bersekongkol dalam Putusan KPPU Nomor 41/KPPUL/2008 adalah Persekongkolan Vertikal yang mana Panitia Pengadaan Barang dan Jasa memfasilitasi PT. Pelita Jaya Mandiri dalam hal kegiatan post bidding dengan Abdul Wahid, serta Persekongkolan Horizontal antara PT. Pelita Jaya Mandiri dengan Abdul Wahid berupa pinjam meminjam perusahaan disertai pengaturan harga penawaran yang dilakukan oleh Abdul Wahid untuk menentukan PT. Pelita Jaya Mandiri sebagai pemenang tender diperkuat dengan adanya Perjanjian Kerja Sama dan Akta Perubahan Anggara Dasar di hadapan Notaris Adi Pinem, SH.

Dalam Putusan Nomor 16/KPPU-L/2014 unsur Persekongkolan Vertikal antara Panitia Pengadaan Barang dan Jasa dengan para terlapor yaitu CV. Burung Nuri, CV. Satriya, dan CV. Ferro terkait tidak melakukan klarifikasi terhadap kesamaan dalam dokumen penawaran tender serta melakukan diskriminasi terhadap peserta yang berpotensi menjadi pemenang dengan cara mengubah beberapa persyaratan tender agar memenangkan CV. Burung Nuri. Selain Persekongkolan secara Vertikal terdapat juga Persekongkolan Horizontal, yang mana telah terjadi pengaturan pemenang antara CV. Burung Nuri dan CV. Satriya yang dibantu oleh Riza Febriant dengan bukti kesamaan dokumen pada saat penawaran tender berlangsung serta telah terjadi kerjasama dalam pembuatan dokumen penawaran antara CV. Burung Nuri dengan Riza Febriant yang diperkuat dengan Surat Perjanjian Kerja Sama di hadapan Notaris Moh. Sugiono.

c. Unsur Pihak Lain

Dalam Putusan KPPU Nomor 41/KPPU-L/2008 pihak lain yang dimaksud adalah Panitia Pengadaan Barang dan Jasa. Hal ini juga senada dengan Putusa KPPU Nomor 16/KPPU-L/2014 pihak lain yang dimaksud adalah Panitia Pengadaan Barang dan Jasa

d. Unsur Persaingan Usaha Tidak Sehat

Persaingan Usaha Tidak Sehat dalam Putusan KPPU Nomor 41/KPPUL/2008 adalah Panitia Pengadaan Barang dan Jasa memfasilitasi PT. Pelita Jaya Mandiri dan Abdul Wahid untuk memenangkan tender dan PT. Pelita Jaya Mandiri dan Abdul Wahid yang melakukan pinjam meminjam perusahaan merupakan tindakan menghambat persaingan usaha. Sedangkan, dalam Putusan KPPU Nomor 16/KPPU-L/2014 unsur persaingan usaha tidak sehat terjadi antara Panitia Pengadaan Barang dan Jasa yang memfasilitasi terjadinya persekongkolan antara para terlapor yang dibantu oleh Riza Febriant. Selain itu tindakan CV. Burung Nuri yang melakukan perjanjian kerjsa sama dengan Riza Febriant untuk 
memenagkan tender tersebut, sehingga menimbulkan persaingan usaha tidak sehat antar peserta tender yang lain.

Melalui Kitab Undang-Undang Hukum Perdata melalui Pasal 1320 disebutkan ada 4 syaarat perjanjian dapat dikatakan sah, yaitu sepakat, kecakapan, suatu hal tertentu dan suatu sebab yang halal.7 Unsur pertama dan kedua merupakan syarat subjektif, karena berkenaan dengan orang atau subjek yang membuat perjanjian. Unsur ketiga dan keempat disebut syarat objektif, karena berkenaan dengan objek yang diperjanjikan. Akibat hukum apabila syarat sahnya perjanjian tidak dapat dipenuhi salah satu saja, maka perjanjian dapat dibatalkan atau batal demi hukum. ${ }^{8}$

Berdasarkan analisis menggunakan Undang-Undang tentang Larangan Praktek Monopoli dan Persaingan Usaha Tidak Sehat dan Pasal 1320 KUHPerdata terhadap kedua kasus tersebut maka Perjanjian yang dilakukan oleh PT. Pelita Jaya Mandiri dengan Abdul Wahid Soenge dan CV. Burung Nuri dengan Riza Febriant tidak memenuhi syarat sah nya perjanjian karena melanggar syarat suatu hal tertentu dalam Pasal 1320 KUHPerdata. Analisis ini berdasarkan keadaan telah dilakukannya sub kontrak secara kesuluruhan kepada pihak ketiga yang mana tidak sesuai dengan Peraturan Presiden dan telah melanggar syarat kausa halal karena tidak sesuai dengan peraturan perundang-undangan, yang merupakan syarat objektif dari perjanjian. Akibatnya, perjanjian tersebut tidak memenuhi syarat objektif perjanjian, maka perjanjian tersebut batal demi hukum dalam arti perjanjian tersebut dari semula dianggap tidak pernah ada atau tidak pernah dibuat.

\section{Tanggung Jawab Notaris Atas Akta Pinjam Meminjam Perusahaan yang Dibuat oleh Para Peserta Tender}

Notaris hadir untuk melayani kepentingan masyarakat yang membutuhkan alat bukti berupa akta autentik sesuai dengan permintan para pihak yang bersangkutan kepada notaris. ${ }^{9}$ Notaris dituntut bekerja profesional dalam menjalankan jabatannya sebagai seorang pejabat umum yang diberi kewenangan membuat akta autentik, tugas notaris sebagai pejabat umum merupakan perpanjangan tangan dari pemerintah guna melayani masyarakat untuk merekam secara tertulis dan autentik hubungan-hubungan hukum antara penghadap. ${ }^{10}$

\footnotetext{
${ }^{7}$ Ibid., hlm. 184.

${ }^{8}$ Ibid., hlm. 191. hlm. 3 .

${ }^{9}$ Habib Adjie, Majelis Pengawas Notaris sebagai Pejabat Tata Usaha Negara, Refika Aditama, Bandung, 2010,

10 Sjaifurrachman dan Habib Adjie, Aspek Pertanggungjawaban Notaris dalam Pembuatan Akta, Mandar Maju, Bandung, 2011, hlm. 66.
} 
Notaris sebagai pejabat umum dituntut bertanggungjawab terhadap akta yang dibuatnya. Apabila akta yang dibuat Notaris mengandung cacat hukum karena kesalahan notaris baik karena kelalaian maupun karena kesengajaan notaris itu sendiri, maka notaris harus memberikan pertanggungjawaban baik secara moral maupun secara hukum. ${ }^{11}$

Berkaitan dengan kasus yang terjadi dalam Putusan KPPU Nomor 41/KPPU-L/2008 dan Putusan KPPU Nomor 16/KPPU-L/2014 Melalui putusan KPPU tersebut Majelis Komisi berpendapat bahwa apa yang dilakukan oleh para pihak ini telah melanggar ketentuan Peraturan Perundang-Undangan melalui Pasal 22 Undang-Undang Nomor 5 Tahun 1999 tentang Larangan Praktek Monopoli dan Persaingan Usaha Tidak Sehat yang melarang para pelaku usaha melakukan persekongkolan dengan pihak lain dalam pelaksanaan tender. Oleh karena telah melanggar ketentuan undang-undang tersebut, maka jika dikaitkan dengan Pasal 1320 KUHPerdata, perjanjian tersebut tidak memenuhi syarat objektif. Akibatnya, perjanjian tersebut batal demi hukum sehingga dianggap tidak pernah ada atau tidak pernah dibuat.

Perbuatan hukum yang ada dalam suatu akta autentik bukanlah perbuatan hukum dari Notaris, melainkan pihak dalam akta itulah yang terkait pada isi dari suatu akta autentik. Apabila dalam suatu akta lahir hak dan kewajiban, maka suatu pihak wajib mematuhi materi apa yang diperjanjikan dan pihak lain berhak untuk menuntut, sedangkan Notaris hanyalah pembuat untuk lahirnya suatu akta autentik. ${ }^{12}$ Terlebih dalam kasus tersebut merupakan akte partij atau akta para pihak, yang mana keterlibatan Notaris hanya sebatas merumuskan perbuatan hukum para pihak kedalam akta autentik dan selanjutnya meresmikan akta tersebut. ${ }^{13}$

\section{Penutup}

Berdasarkan Putusan KPPU Nomor 41/KPPU-L/2008 Perjanjian yang dibuat oleh PT. Pelita Jaya Mandiri dengan Abdul Wahid Soenge, dan Putusan KPPU Nomor 16/KPPU-L/2014 Perjanjian yang dibuat oleh CV. Burung Nuri dengan Riza Febriant tidak memenuhi syarat objektif suatu perjanjian yaitu Suatu sebab yang halal karena melanggar Pasal 22 Undang-Undang tentang Larangan Praktik Monopoli dan Persaingan Usaha Tidak Sehat serta Peraturan Presiden tentang Pengadaan Barang dan Jasa sehingga perjanjian tersebut batal demi hukum.

\footnotetext{
${ }^{11}$ Putri A.R, Perlindungan Hukum Terhadap Notaris, PT. Sofmedia, Jakarta, 2011, hlm. 8.

12 G.H.S. Lumban Tobing, Peraturan Jabatan Notaris, Erlangga, Jakarta, 1999, hlm. 39.

13 Djoko Sukisno, "Pengambilan Foto Copi Minuta Akta dan Pemanggilan Notaris", Jurnal Mimbar Hukum, Volume 20 Nomor 1, 2008, hlm. 53.
} 
Dalam perjanjian yang dibuat oleh PT. Pelita Jaya Mandiri dengan Abdul Wahid Soenge dihadapan Notaris Adi Pinem, dan Perjanjian yang dibuat oleh CV. Burung Nuri dengan Riza Febriant dihadapan Notaris Moh. Sugiono, Notaris tidak dapat bertanggungjawab terkait akta tersebut dikarenakan akta para pihak merupakan kehendak para pihak dan Notaris bukan pihak dalam akta tersebut.

Dalam penelitian ini, penulis memberi rekomendasi agar pengaturan Persekongkolan Tender dalam hukum persaingan usaha lebih ditekankan terkhusus dengan adanya praktik pinjam meminjam bendera perusahaan. Hal ini dapat dilakukan dengan melakukan amandemen terhadap Undang-Undang No. 5 Tahun 1999 tentang Larangan Praktik Monopoli dan Persaingan Usaha Tidak Sehat supaya lebih menekankan agar para pelaku usaha ini dilarang melakukan praktek persekongkolan tender. Selain dengan amandemen peraturan juga perlu adanya harmonisasi antar peraturan dalam penanganan kasus persekongkolan tender supaya tidak ada yang dirugikan baik pelaku usaha maupun konsumen yang menikmati barang dan/jasa dari pelaku usaha peserta tender. Peran notaris dalam mencegah adanya praktek persekongkolan dalam tender diperlukan dengan tidak membantu pelaku usaha melegalkan suatu perjanjian yang dapat menghambat persaingan usaha secara sehat.

\section{Daftar Pustaka}

\section{Buku}

A.R., Putri, Perlindungan Hukum Terhadap Notaris, PT. Sofmedia, Jakarta, 2011.

Adjie, Habib, Majelis Pengawas Notaris sebagai Pejabat Tata Usaha Negara, Refika Aditama, Bandung, 2010.

Fahmi Lubis, Andi, Hukum Persaingan Usaha Antra Teks dan Konteks, Komisi Pengawas Persaingan Usaha, Jakarta, 2009.

Hery, SE, Hukum Bisnis, PT. Grasindo, Jakarta, 2020.

Lumban Tobing, G.H.S., Peraturan Jabatan Notaris, Erlangga, Jakarta, 1999.

Sjaifurrachman dan Habib Adjie, Aspek Pertanggungjawaban Notaris dalam Pembuatan Akta, Cetakan Pertama, Madar Maju, Bandung, 2011.

Thian, Alexander, Hukum Dagang, CV. Andi Offset, Yogyakarta, 2021.

Usman, Rachmadi, Hukum Persaingan Usaha Di Indonesia, Sinar Grafika, Jakarta, 2013.

Yudha Hernoko, Agus, Hukum Perjanjian Asas Proposionalitas dalam Kontrak Komersial, LaksBang Mediatama, Yogyakarta, 2008.

\section{Jurnal}

Djoko Sukisno, "Pengambilan Foto Copi Minuta Akta dan Pemanggilan Notaris", Jurnal Mimbar Hukum, Volume 20 Nomor 1, 2008. 